\title{
Sistem Pendukung Keputusan Dalam Menentukan Pengguna Listrik Subsidi Dan Nonsubsidi Menggunakan Metode Fuzzy Mamdani (Studi Kasus : PT. PLN Tanjung Balai)
}

\author{
Adi Widarma ${ }^{1}$, Hana Kumala ${ }^{2}$ \\ ${ }^{1,2}$ Fakultas Teknik Jurusan Teknik Informatika Universitas Asahan \\ Jl. Jend Ahmad Yani Kisaran Sumatera Utara \\ adiwidarma10@gmail.com, ${ }^{3}$ hanakum94@gmail.com
}

\begin{abstract}
Abstrak - Program subsidi listrik adalah salah satu program penanggulangan kemiskinan dengan memberikan dana bantuan subsidi listrik kepada rumah tangga miskin dan tidak mampu yang dibayar oleh Pemerintah Indonesia kepada PT. PLN (persero). Pada PT. PLN (Persero) Area Rantau Prapat Rayon Tanjung Balai yang terletak di Jl. Jendral Sudirman memiliki permasalahan yang dihadapi yaitu mengenai anggaran subsidi ternyata selama ini banyak yang salah sasaran, sebagian besar dana subsidi jatuh ke orang-orang yang mampu secara ekonomi. Pemerintah menerapkan kebijakan subsidi listrik tepat sasaran, subsidi harus benar-benar dinikmati oleh orang-orang miskin. Untuk memberikan subsidi listrik kepada rumah tangga miskin dan rumah tangga tidak mampu baik manusia maupun instansi tidak lepas dari sistem teknologi informasi. Sistem ini biasanya dinamakan dengan Sistem pendukung keputusan yang dirancang untuk membantu dalam mengambil sebuah keputusan dimana tidak seorang pun tahu secara pasti bagaimana keputusan seharusnya dibuat. Persoalan sistem pengambilan keputusan menggunakan sistem logika fuzzy sangat cocok untuk penalaran pasti atau perkiraan, terutama untuk sistem dengan model matematika yang sulit dan data-data yang tidak tepat untuk mendapatkan sebuah keputusan yang pasti.
\end{abstract}

Kata Kunci - Sistem Pendukung Keputusan, Subsidi Listrik, Logika Fuzzy.

\section{PENDAHULUAN}

Perkembangan teknologi semakin hari semakin terus berkembang, dengan semakin berkembangnya ilmu komputer ini hampir tidak bisa dipisahkan dari kehidupan sehari-hari, karena hampir seluruh kegiatan manusia dilakukan dengan memanfaatkan teknologi komputer dalam suatu organisasi atau perusahaan. PT Perusahaan Listrik Negara atau biasa disebut PT. PLN adalah Badan Usaha Milik Negara yang masih menyediakan subsidi tarif tenaga listrik untuk rumah tangga.

Di dalam Undang-Undang Peraturan Menteri Energi dan Sumber Daya Mineral Republik Indonesia Nomor 29 Tahun 2016 tentang Mekanisme Pemberian Subsidi Tarif Tenaga Listrik Untuk Rumah Tangga. Program subsidi listrik adalah salah satu program penanggulangan kemiskinan dengan memberikan dana bantuan subsidi listrik kepada rumah tangga miskin dan tidak mampu yang dibayar oleh Pemerintah Indonesia kepada PT. PLN (persero). Berdasarkan permasalahan di atas, maka hal inilah yang menjadi alasan penulis mengajukan judul penelitian yaitu "Sistem Pendukung Keputusan Dalam Menentukan Pengguna Listrik Subsidi Dan Nonsubsidi Pada PT.PLN (Persero) Tanjung Balai Menggunakan Metode Fuzzy Mamdani”. Dalam adanya sistem tersebut diharapkan dapat membantu dalam pengambilan keputusan untuk menentukan calon penerima subsidi dengan cepat, dan tepat.

\section{LANDASAN TEORI}

A. Sistem

Dalam buku karangan Al-Bahra Bin Ladjamudin (2015:3) mengutip pendapat Lucas (1989) bahwa sistem adalah suatu komponen atau variabel yang terorganisir, saling berinteraksi, saling bergantung, satu sama lain dan terpadu.

Berdasarkan beberapa definisi sistem menurut para peneliti, maka penulis menyimpulkan bahwa sistem adalah sekumpulan dua atau lebih komponen ataupun objek yang saling membutuhkan satu dengan lainnya yang apabila diproses akan menghasilkan suatu output yang bermanfaat bagi pengguna.

\section{B. Keputusan}

Keputusan merupakan kesimpulan terbaik yang diperoleh setelah mengevaluasi berbagai alternatif. Menurut James A.F. Stoner Keputusan adalah pemilihan diantara suatu alternatif. Definisi ini mengandung tiga pengertian yaitu ada pilihan atas dasar logika, ada beberapa alternatif yang harus dan dipilih satu yang terbaik dan ada tujuan yang ingin dicapai dan keputusan itu makin mendekatkan pada tujuan tersebut.

\section{Sistem Pendukung Keputusan}

Definisi sistem pendukung keputusan dalam bukunya Abdil Kadir (2010:108) Sistem pendukung keputusan (SPK) atau Decision Support System (DSS) adalah sistem informasi interaktif yang menyediakan informasi, pemodelan, dan pemanipulasian data yang digunakan untuk membantu pengambilan keputusan pada situasi yang semiterstruktur dan situasi yang tidak terstruktur dimana tidak seorang pun tahu secara pasti bagaimana keputusan seharusnya dibuat (Alter, 2002). Konsep DSS pertama kali dikemukakan oleh Scott-Morton pada tahun 1971 (Turban, McLean, dan Wetherbe, 1999). Beliau mendefinisikan cikal bakal DSS tersebut sebagai Sistem berbasis komputer yang interaktif, yang membantu pengambil keputusan 
menggunakan data dan model untuk memecahkan persoalan-persoalan tidak terstruktur.

Beberapa Fungsi sistem pendukung keputusan, yaitu:

1. DSS lebih ditujukan untuk mendukung managemen dalam melakukan pekerjaaan yang bersifat analitis, dalam situasi yang kurang terstruktur dan dengan kriteria yang kurang jelas.

2. DSS tidak dimaksudkan untuk mengotomasikan pengambilan keputusan, tetapi memberikan perangkat interaktif yang memungkinkan pengambil keputusan dapat melakukan berbagai analisis dengan menggunakan model-model yang tersedia.

\section{Subsidi Listrik}

Di dalam Undang-Undang Peraturan Menteri Energi dan Sumber Daya Mineral Republik Indonesia Nomor 29 Tahun 2016 tentang Mekanisme Pemberian Subsidi Tarif Tenaga Listrik Untuk Rumah Tangga. Subsidi listrik merupakan sejumlah dana yang dibayar oleh Pemerintah Indonesia kepada PT. PLN (Persero) Dengan adanya subsidi tersebut, diharapkan ketersediaan listrik dapat terpenuhi, kelangsungan penyediaan listrik dapat berjalan stabil, serta memberi kesempatan kepada pelanggan yang kurang mampu dan masyarakat yang belum terjangkau pelayanan PT.PLN untuk dapat ikut dapat menikmati energi listrik.

\section{E. Logika Fuzzy}

logika fuzzy diperkenalkan oleh Prof. Lotfi Astor Zadeh pada 1962. Dalam bukunya T. Sutojo, Edy Mulyanto, dan Dr. Vincent Suhartono (2010:211) Logika fuzzy adalah metodelogi sistem kontrol pemecahan masalah, yang cocok untuk diimplementasikan pada sistem, mulai dari sistem yang sederhana, sistem kecil, embedded system, jaringan PC, multi-channel atau workstation berbasis akuisisi data, dan sistem kontrol. dalam logika fuzzy memungkinkan nilai keanggotaan berada di antara 0 atau 1. Artinya, bisa saja suatu keadaan mempunyai dua nilai "Ya dan Tidak", "Benar dan Salah", "Baik dan Buruk" secara bersamaan, namun besar nilainya tergantung pada bobot keanggotaan yang dimilikinya.

\section{F. $\quad$ Metode Mamdani}

Metode Mamdani pertama kali diperkenalkan oleh Ibrahim Mamdani pada tahun 1975. Dalam bukunya T. Sutojo, Edy Mulyanto, dan Dr. Vincent Suhartono (2010:235) Metode ini merupakan metode yang paling sederhana dan paling sering digunakan untuk penelitian dibanding metode yang lain. Dalam metode mamdani, output dari aturan fuzzy ditentukan dengan operasi MIN. selanjutnya output-output dari aturan fuzzy diinterferensikan menggunakan operasi MAX. Oleh karena itu metode mamdani juga disebut dengan metode MIN-MAX ( $\min \max$ inferencing). Logika fuzzy Mamdani merupakan salah satu metode yang sangat fleksibel dan memiliki toleransi pada data yang ada. Fuzzy Mamdani memiliki kelebihan yakni lebih intuitif, diterima oleh banyak pihak.

Untuk mendapatkan output, diperlukan 4 tahap berikut:

1. Fuzzifikasi

2. Pembentukan basis pengetahuan fuzzy (rule dalam bentuk IF THEN)

3. Aplikasi fungsi implikasi mengunakan fungsi MIN dan komposisi antar rule menggunakan fungsi MAX (menghasilkan himpunan baru)

4. Defuzzifikasi menggunakan metode Centroid.

Menurut Chabibi Aulia Rahman Al Hasmy (Muhammad Dedi Irawan, 2017) Untuk mendapatkan output, diperlukan 4 tahan terbobot :

a. Pembentukan himpunan fuzzy Pada metode Mamdani, baik variabel input maupun variabel output dibagi menjadi satu atau lebih himpunan fuzzy.

b. Aplikasi fungsi implikasi Pada metode Mamdani, fungsi implikasi yang digunakan adalah Min.

c. Komposisi aturan

Tidak seperti penalaran monoton, apabila sistem terdiri dari beberapa aturan, maka inferensi diperoleh dari kumpulan dan korelasi antar aturan. Ada 3 metode yang digunakan dalam melakukan inferensi sistem fuzzy, yaitu : Max, Additive dan Probabilistik OR (PROBOR).

d. Penegasan (Defuzzy)

Input dari proses defuzzikasi adalah suatu himpunan fuzzy yang diperoleh dari komposisi aturan-aturan fuzzy, sedangkan output yang dihasilkan merupakan suatu bilangan pada domain himpunan fuzzy tersebut. Sehingga jika diberikan suatu himpunan fuzzy dalam range tertentu, maka harus dapat diambil suatu nilai crisp tertentu sebagai output.

G. Pemodelan Berorientasi Objek Menggunakan Unified Modeling Language (UML)

Unified Modeling Language (UML) adalah standarisasi bahasa pemodelan untuk membangun perangkat lunak yang dibangun dengan menggunakan teknik pemodelan berorientasi objek (Shalahuddin dan Rosa, 2013). UML sendiri juga memberikan standar penulisan sebuah sistem blue print, yang meliputi konsep bisnis proses, penulisan kelas-kelas dalam bahasa program yang spesifik, skema database, komponen-komponen yang diperlukan dalam sistem software

1. Use Case Diagram

Menurut Shalahuddin dan Rosa (Winda Aprianti, 2016) Use case diagram merupakan sebuah interaksi antara satu atau lebih aktor dengan sistem informasi yang akan dibuat.

2. Diagram Aktivitas (Activity Diagram)

Activity Diagram menggambarkan workflow (aliran kerja) atau aktivitas dari sebuah sistem atau proses bisnis. Menurut Shalahuddin dan Rosa (Winda Aprianti, 2016) Activity diagram 
merupakan state diagram khusus, di mana sebagian besar state adalah action dan sebagian besar transisi di-trigger oleh selesainya state sebelumnya (internal processing).

3. Diagram Diagram Kelas (Class Diagram)

Diagram Kelas (Class Diagram) merupakan hubungan antar kelas dan penjelasan detail tiaptiap kelas di dalam model desain dari suatu sistem, juga memperlihatkan aturan-aturan dan tanggung jawab entitas yang menentukan perilaku sistem.

\section{H. Matlab}

Dalam bukunya R.H, Sianipar (2010:211) MATLAB merupakan akronim dari kata kata Matrix Laboratory yaitu suatu paket perangkat lunak yang memampukan seseorang untuk melakukan komputasi matematik, menganalisa data, mengembangkan algoritma, melakukan simulasi dan pemodelan, dan menghasilkan tampilan grafik dan antarmuka grafikal.

\section{METODE PENELITIAN}

\section{A. Rancangan Penelitian}

Rancangan penelitian adalah suatu kesatuan, rencana terinci dan spesifik mengenai cara memperoleh, menganalisis, dan menginterprestasi. Dengan rancangan penelitian, seseorang peneliti mampu mengambil sikap dan keputusan yang tepat dalam mengatasi masalah penelitian.

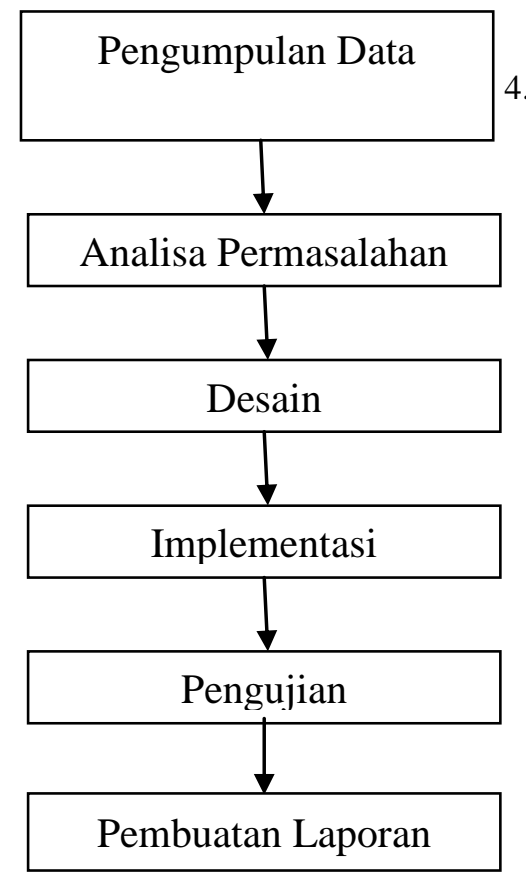

Gambar 1 Kerangka Kerja

\section{B. Metode Penelitian}

Dalam pembuatan aplikasi ini, metode yang penulis gunakan berupa metode observasi, yang nantinya digunakan untuk memperoleh data-data yang dibutuhkan dalam pembuatan aplikasi. Metode observasi ini berupa pengumpulan data dari sumbersumber yang berkaitan dengan sistem pendukung keputusan dalam menentukan pengguna listrik subsidi dan nonsubsidi yaitu di PT.PLN (Persero) Tanjung Balai J1. Jenderal Sudirman.

\section{Objek Penelitian}

Objek penelitian merupakan permasalahan yang diteliti. Objek penelitian dilakukan pada PT.PLN (Persero) Tanjung Balai Jl. Jenderal Sudirman.

\section{Definisi Operasional Variabel}

Operasional variabel berisikan indikatorindikator dari suatu variabel yang memungkinkan peneliti mengumpulkan data yang relevan untuk variabel tersebut. Adapun variabel-variabel yang akan digunakan untuk menentukan pengguna listrik subsidi dan nonsubsidi, yaitu daya listrik yang digunakan, penghasilan atau gaji, tanggungan anak, kondisi rumah, dan wilayah perumahan.

\section{E. Teknik Pengumpulan Data}

Pada bab ini akan dijelaskan tentang sumber dan teknik pengumpulan data yang diperoleh peneliti dalam penyusunan penelitian.

\section{Data Primer}

Yaitu data yang diperoleh secara langsung dari sumber penelitian atau dari instansi yang menjadi objek penelitian.

2. Data Sekunder

Yaitu data yang diperoleh dengan mengumpulkan terlebih dahulu teori yang ada kaitannya dengan masalah yang diteliti. Seperti: daftar pustaka, jurnal, buku yang berkaitan dengan sistem pendukung keputusan

\section{F. Metode Analisa Data}

Analisis data merupakan bagian integral dari proses penelitian yang dituangkan baik dalam bentuk tulisan atau tidak. Dalam metode analisis data penulis menggunakan metode Mamdani dimana observasi dilakukan di PT.PLN (Persero) area Rantau Prapat rayon Tanjung Balai Jl. Jenderal Sudirman.

\section{ANALISA DAN PEMBAHASAN}

\section{A. Analisa Sistem}

Analisa sistem merupakan penguraian dari suatu sistem yang utuh ke dalam bagian-bagian komponennya dengan maksud untuk mengidentifikasi dan mengevaluasi permasalahan. Hal-hal yang dianalisa pada tahap analisa sistem adalah analisa masalah yang sering dialami pengguna listrik PT. PLN (Persero) Tanjungbalai.

\section{B. Analisa Masalah}

Di dalam Undang-Undang Peraturan Menteri Energi dan Sumber Daya Mineral Republik 
Indonesia Nomor 29 Tahun 2016 tentang Mekanisme Pemberian Subsidi Tarif Tenaga Listrik Untuk Rumah Tangga. Berdasarkan identifikasi masalah dapat di tentukan pengguna listrik subsidi dan nonsubsidi pada PT PLN (Persero) Tanjungbalai, antara lain :

1. Masih menggunakan cara yang manual dalam penentuan listrik subsidi maupun nonsubsidi.

2. Membutuhkan waktu yang relatif lama.

3. Sebagian besar dana subsidi jatuh ke orangorang yang mampu secara ekonomi .

\section{Pembentukan Variabel dan Himpunan Fuzzy (Fuzzifikasi) \\ Variabel telah ditentukan maka proses} selanjutnya adalah menentukan himpunan fuzzy sesuai masing-masing variabel.

TABEL 1.

VARIABEL PENGHASILAN

\begin{tabular}{|c|c|c|c|}
\hline No & Variabel & Batas Nilai & Himpunan \\
\hline \multirow{3}{*}{1} & \multirow{4}{*}{ Penghasilan } & $0-\leq 3$ juta & Rendah \\
\cline { 3 - 4 } & & $\geq 1$ juta $-\leq 5$ juta & Sedang \\
\cline { 3 - 4 } & & $\geq 3$ juta $-\leq 6$ juta & Tinggi \\
\hline
\end{tabular}

TABEL 2.

VARIABEL TANGGUNGAN

\begin{tabular}{|c|c|c|c|}
\hline \multirow{2}{*}{ No } & Variabel & Batas Nilai & Himpunan \\
\hline \multirow{2}{*}{1} & \multirow{2}{*}{ Tanggungan } & $0-\leq 4$ orang & Sedikit \\
\cline { 3 - 4 } & & $\begin{array}{c}\geq 1 \text { orang }-\leq 7 \\
\text { orang }\end{array}$ & Normal \\
\cline { 3 - 4 } & $\begin{array}{c}\geq 4 \text { orang }-\leq 9 \\
\text { orang }\end{array}$ & Banyak \\
\hline
\end{tabular}

TABEL 3.

VARIABEL KONDISI RUMAH

\begin{tabular}{|c|c|c|c|}
\hline No & Variabel & Batas Nilai & Himpunan \\
\hline \multirow{3}{*}{1} & \multirow{3}{*}{$\begin{array}{l}\text { Kondisi } \\
\text { Rumah }\end{array}$} & Nilai 0 - nilai $\leq 10$ & Buruk \\
\hline & & Nilai $\geq 5-$ nilai $\leq 15$ & Sedang \\
\hline & & Nilai $\geq 15-$ nilai $\leq 50$ & Baik \\
\hline
\end{tabular}

TABEL 4

VARIABEL DAYA LISTRIK

\begin{tabular}{|c|c|c|c|}
\hline No & Variabel & Batas Nilai & Himpunan \\
\hline \multirow{4}{*}{1} & \multirow{4}{*}{ Daya Listrik } & 0 - $\leq 900 \mathrm{VA}$ & Rendah \\
\cline { 3 - 4 } & & $\geq 450 \mathrm{VA}-\leq 1300 \mathrm{VA}$ & Sedang \\
\cline { 3 - 4 } & & $\geq 900 \mathrm{VA}-\leq 2200 \mathrm{VA}$ & Tinggi \\
\hline
\end{tabular}

TABEL 5.

VARIABEL WILAYAH RUMAH

\begin{tabular}{|c|c|c|c|}
\hline No & Variabel & Batas Nilai & Himpunan \\
\hline \multirow{4}{*}{1} & \multirow{3}{*}{1} & Wilayah \\
\cline { 3 - 4 } & Perumahan & Nilai $0-$ nilai $\leq 10$ & Kurang \\
\cline { 3 - 4 } & & Nilai $\geq 8-$ nilai $\leq 12$ & Cukup \\
\cline { 3 - 4 } & & Nilai $\geq 10-$ nilai $\leq 15$ & Sesuai \\
\hline
\end{tabular}

TABEL 6.

VARIABEL OUTPUT

\begin{tabular}{|c|c|c|c|}
\hline No & Variabel & Batas Nilai & Himpunan \\
\hline \multirow{3}{*}{1} & \multirow{3}{*}{ Golongan } & Nilai 0 - nilai $\leq 900$ & Subsidi \\
\cline { 3 - 4 } & & $\begin{array}{c}\text { Nilai } \geq 450-\text { nilai } \leq \\
1300\end{array}$ & \\
& & & Dipertimbangkan \\
\cline { 3 - 4 } & & $\begin{array}{c}\text { Nilai } \geq 900-\text { nilai } \leq \\
2200\end{array}$ & NonSubsidi \\
\hline
\end{tabular}

\section{Derajat Keanggotaan}

1. Penghasilan

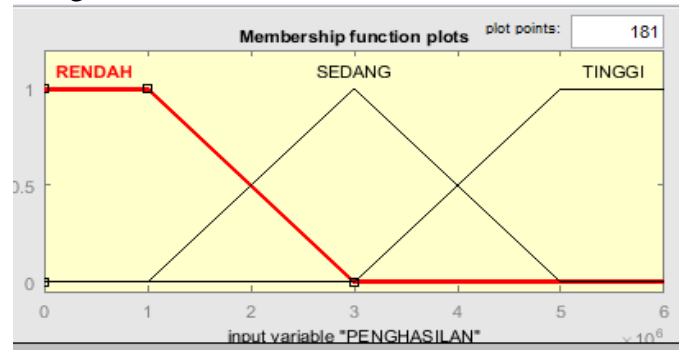

Gambar 2 Derajat Keanggotaan Penghasilan

2. Tanggungan

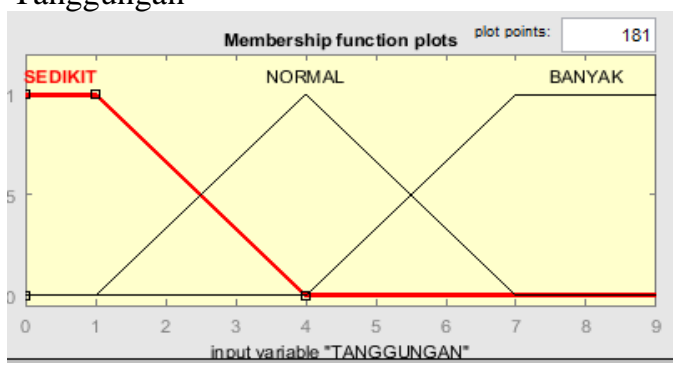

Gambar 3 Derajat Keanggotaan Tanggungan

3. Kondisi Rumah

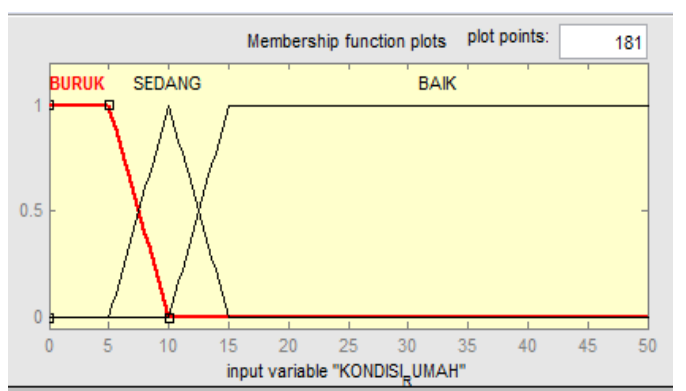

Gambar 4 Derajat Keanggotaan Kondisi rumah 
4. Daya Listrik

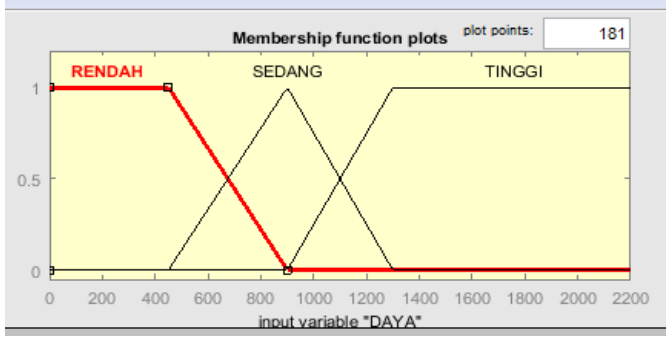

Gambar 5 Derajat Keanggotaan Daya Listrik

5. Wilayah Perumahan

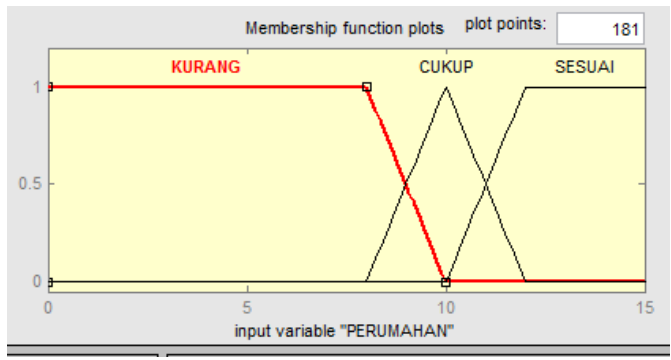

Gambar 6 Derajat Keanggotaan Wilayah Perumahan

6. Output untuk Golongan

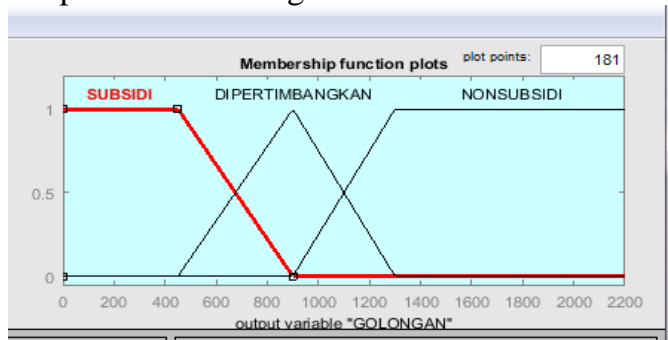

Gambar 7 Derajat Keanggotaan Output Golongan

\section{E. Perancangan Sistem}

1. Use Case Diagram

Perancangan model dengan use case diagram menggambarkan perilaku sistem yang dibuat.

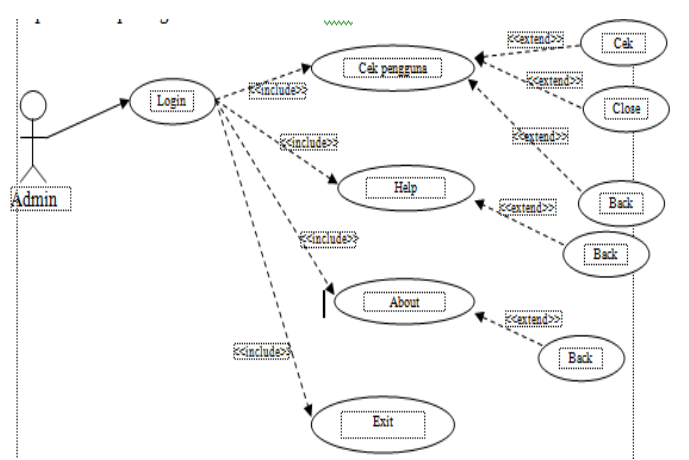

Gambar 8 Use Case
2. Class Diagram

Perancangan aplikasi pengguna listrik menggunakan class diagram dapat dilihat pada gambar sebagai berikut :

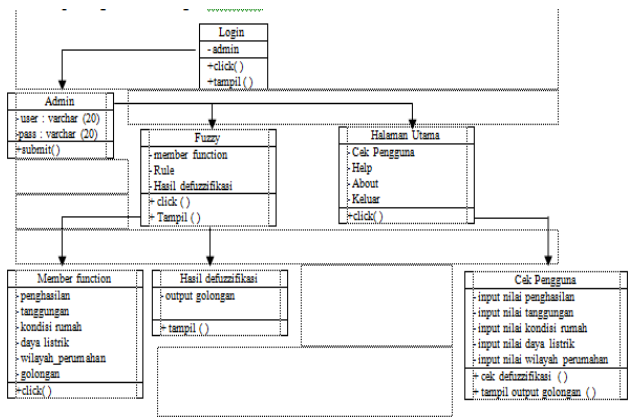

Gambar 9 Class Diagram

3. Activity Diagram

Perancangan Activity Diagram mengambarkan bagaimana alur aktivitas yang terjadi antara admin atau user didalam sebuah sistem. Agar lebih jelas berikut di bawah ini gambaran Activity Diagram admin.

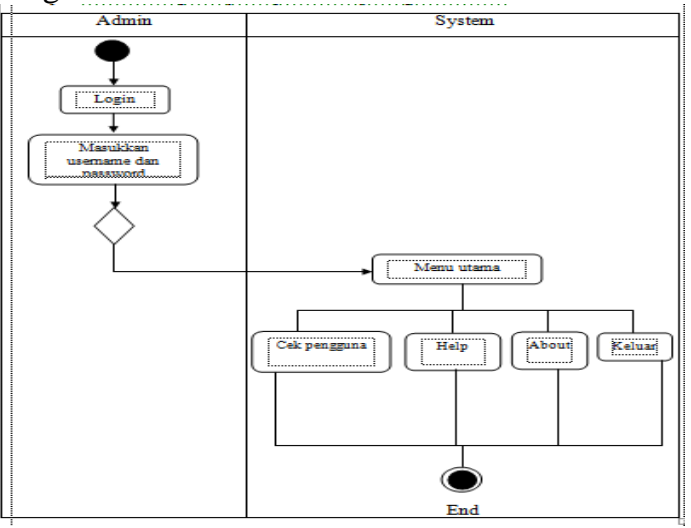

Gambar 10 Activity Diagram

\section{F. Implementasi Hasil Rancangan Program}

Implementasi merupakan tahapan pengujian sistem yang dibangun. Adapun hasil implementasi dapat dilihat pada sub bagian dibawah ini.

1. Tampilan Menu Login

Tampilan menu login merupakan halaman untuk admin login agar dapat masuk kedalam sistem untuk mengkelola data. Pada tahap ini admin harus memasukkan user dan password nya dan kemudian submit. Adapun gambar dapat dilihat dibawah ini.

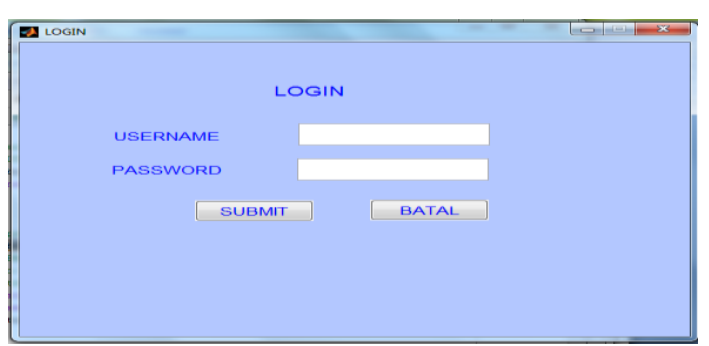

Gambar 11 Tampilan Menu Login 
2. Tampilan Menu Utama Admin

Tampilan menu ini merupakan halaman dimana terdapat beberapa tombol button. Adapun gambarnya adalah sebagai berikut.

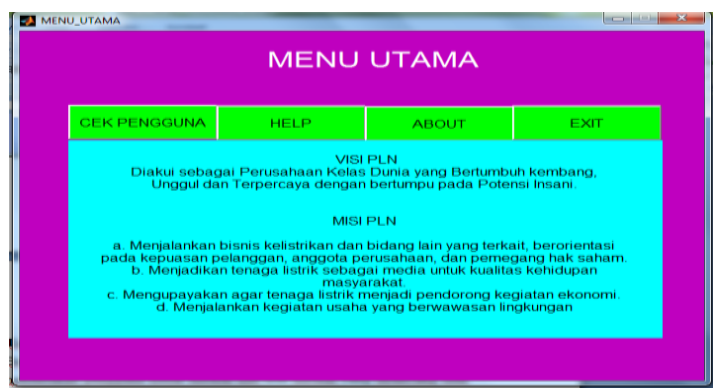

Gambar 12 Tampilan Menu Utama

3. Tampilan Menu Cek Pengguna

Tampilan halaman ini merupakan halaman untuk menginputkan data pengguna listrik berdasarkan variabel yang ada. Selanjutkan dengan mengecek penentuan golongannya. Dapat dilihat pada gambar dibawah ini.

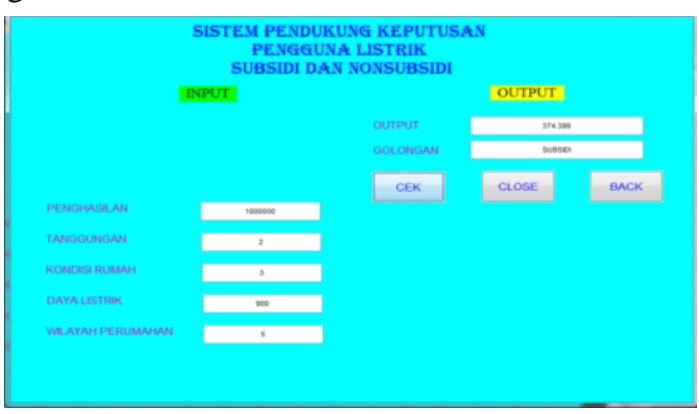

Gambar 13 Tampilan Menu Cek Pengguna

4. Tampilan Menu Help

Halaman ini merupakan halaman untuk memberikan bantuan kepada admin. Adapun gambarnya dapat dilihat dibawah ini.

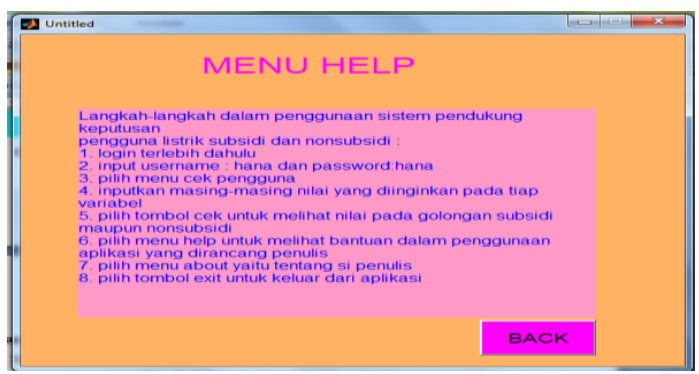

Gambar 14 Tampilan Menu Help
5. Tampilan Menu About

halaman ini merupakan halaman dimana berisikan tentang sistem yang telah dirancang oleh penulis. Berikut dapat dilihat pada gambar dibawah ini.

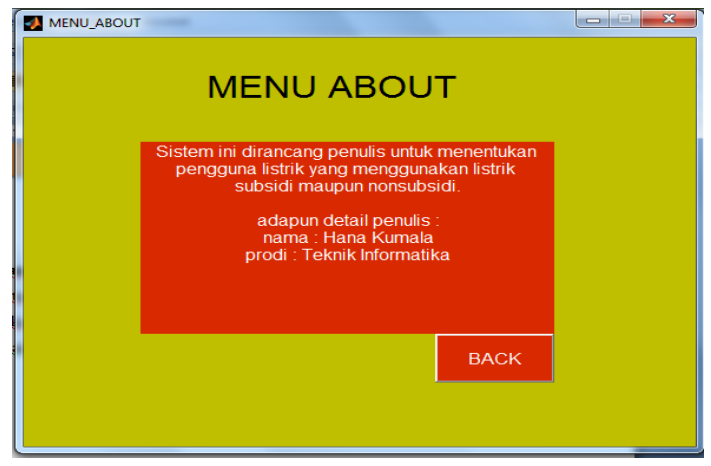

Gambar 15 Tampilan Menu About

\section{PENUTUP}

A. Kesimpulan

Berdasarkan hasil penelitian yang dilakukan dan hasil pembahasan yang telah diuraikan pada babbab sebelumnya, maka penulis dapat menyimpulkan hal-hal sebagai berikut:

1. Adapun sistem pendukung keputusan yang dibangun ini dapat membantu seorang managerdalam menentukan pengguna listrik subsidi dan nonsubsidi terkhusus di PT. PLN Rayon Tanjung Balai.

2. Sistem pendukung keputusan ini telah mampu menampilkan golongan dari calon pengguna, dengan maksud agar subsidi listrik benar-benar dapat dinikmati oleh Rumah Tangga tepat sasaran.

3. Sistem ini dapat menjadi bahan pertimbangan dalam menentukan pengguna listrik subsidi atau nonsubsidi.

4. Variabel yang lebih spesifik berdasarkan hasil proses metode fuzzy mamdani adalah penghasilan, kondisi rumah, dan daya listrik yang digunakan. Karna jika penghasilan rendah, kondisi rumah buruk, dan daya yang digunakan rendah maka pengguna listrik digolongkan pada bagian subsidi. Jika penghasilan tinggi, kondisi rumah baik, dan daya yang digunakan tinggi maka pengguna listrik digolongkan pada bagian nonsubsidi.

\section{B. Saran}

Berdasarkan hasil penelitian yang dilakukan penulis, ada beberapa saran untuk pengembangan sistem lebih lanjut, diantaranya:

1. Sistem yang penulis rancang ini masih bersifat offline dan dapat dikembangkan lagi menjadi bersifat online.

2. Sistem pendukung keputusan ini juga dapat dikembangkan dengan menggunakan metode lain 
seperti metode Tsukomoto, sugeno sehingga dapat dilihat keakuratan datanya.

3. Sistem ini dirancang untuk membantu pihak manager dalam proses pengambilan keputusan, bukan untuk menggantikan fungsi manager.

\section{DAFTAR PUSTAKA}

[1] Abdil Kadir, 2013. Pengenalan Sistem Informasi. Yogyakarta: Penerbit Andi.

[2] Al- Bahra Bin Ladjamuddin, 2015. Analisis Dan Desain sistem Informasi. Yogyakarta: Penerbit Graha Ilmu.

[3] Dwi Citra Hartini, Dkk. 2013. Sistem Pendukung Keputusan Pemilihan Hotel Dikota Palembangdengan Metode Simple Additive Weighting $(S A W)$. Jurnal Sistem Informasi, Vol. 5. No. 1.

[4] Hasan Abdurrahman, Dkk. 2014. Aplikasi Pinjaman Pembayaran Secara Kredit Pda Bank Yudha Bhakti. Jurnal Computech Dan Bisnis, Vol. 8. No. 2.

[5] Hetty Rohayani. 2013. Analisis Sistem Pendukung Keputusan Dalam Memilih Program Studi Menggunakan Metode Logika Fuzzy. Jurnal Sistem Informasi, Vol. 5. No. 1.

[6] Lasminiasih, Dkk. 2016. Perancangan Sistem Informasi Kredit Mikro Mahasiswa Berbasis Web. Jurnal Sistem Informasi, Vol. 8. No. 1.

[7] Muhammad Dedi Irawan. 2017. Sistem Pendukung Keputusan Menentukan Matakuliah Pilihan pada Kurikulum Berbasis KKNI Menggunakan Metode Fuzzy Sugeno. JURNAL MEDIA INFOTAMA. Vol.13. No.1.

[8] R. H, Sianipar. 2010. Pemograman Matlab. Bandung: Penerbit Informatika.

[9] Sundari Retno Handayani. 2013. Fuzzy Mamdani Dalam Menentukan Tingkat Keberhasilan Dosen Mengajar . Seminar Nasional Informatika, semnasIF2013.

[10] T. Sutojo, dkk. 2010. Kecerdasan Buatan. Yogyakarta: Penerbit Andi.

[11] Tata Sutabri. 2012. Analisis Sistem Informasi. Yogyakarta: Penerbit Andi.

[12] Undang-Undang Peraturan Menteri Energi Dan Sumber Daya Mineral Republik Indonesia Nomor 29 Tahun 2016. Mekanisme Pemberian Subsidi Tarif Tenaga Listrik Untuk Rumah Tangga.

[13] Winda Aprianti, Dkk. 2016. Sistem Informasi Kepadatan Penduduk Desa Kecamatan BatiBati Kabupatn Tanah Laut. Jurnal Sains Dan Informatika, Vol. 2. No. 1.

[14] Yeremia Yuliawan, Dkk. 2013. Pengembangan Sistem Informasi Pendataan Jemaat Gereja Masehi Advent Hari Ketujuh Konferens Jawa Kawasan Timur Berbasis Web. Jurnal Sistem Informasi, Vol. 2. No. 2. 